\title{
Parameters Identification for Three Groups of Squirrel Induction Motor
}

\author{
Mervet A. Shanab ${ }^{1, *}$ \\ ${ }^{1}$ Department of Electrical Engineering, University of Menofia, Shebin El-kom (32511), Egypt \\ *Corresponding authors email: mervatshanab3@gmail.com \\ DOI: https://doi.org/10.54392/irjmt2211 \\ Received: 04-12-2021, Revised: 27-12-2021; Accepted: 27-12-2021, Published: 30-12-2021
}

Abstract: This paper presents a developed method to calculate the parameters for thirty-three squirrel cage induction motors operating at three-phase ac voltage of 380 volts. These motors are the total product of an Egyptian factory holding a license from SIEMENS international company to fabricate all parts of these motors. The parameters of all mentioned motors are computed based on the proposed method. Then, the performance characteristics of these motors are investigated at full-load using the conventional equivalent circuit in order to validate the proposed method. The obtained curves achieve significant convergence with the full-load values provided by the data sheets of investigated motors. This confirms the validity of the proposed method.

Keywords: Induction motors, Equivalent circuit parameters, SIEMENS

\section{Introduction}

The modern inverters used for Induction Motor (IM) control, are provided by two developed techniques to improve the motor performance characteristics. They are the field-oriented control and direct torque control [1-6]. However, during the operation at first time, the motor full-load data should be identified to the inverter. Then the inverter computes the initial values of motor parameters needed to start the control process [7-9]. Hence, determination of IM parameters based on fullload data is of vital importance.

The methods used to determine the motor parameters can be basically classified into five categories as mentioned in [10]. They are :(i) Parameter estimation based on machine geometry; (ii) Parameter estimation based on steady-state motor models; (iii) Frequency-domain parameter estimation; (iv) Time-domain parameter estimation; (v) Real-time parameter estimation. The present research focuses on parameter estimation based on full-load data, that following the second category. Literature survey about some of the aforementioned methods is detailed in the following sections.

Genetic algorithm has been adopted to obtain the IM parameters from manufacture data as in [11]. The authors depended on the equations of power flow in IM to derive the parameters. Although all losses of the machine are considered in the model, significant deviation was found in some parameters values, yielding less accuracy in calculations. Another work used also the equations of power flow in IM to derive the parameters based on manufacture data [12]. However, an approximation in core loss calculation was made resulting in less accurate results. In addition, the author applied the model merely to one motor.

Throughout [13], an analytical method has been presented to calculate the I.M parameters from name-plate data. It was applied to large number of motors with different power ratings and achieved acceptable results. However, for small motors of power rating less than 5HP, the results lacked of accuracy. Another analytical method based on manufacturer data has been adopted as in [14]. A set of nonlinear equations were derived from the equivalent circuit, then solved using the least-squares based algorithm to obtain the motor parameters. However, the stator resistance was approximated to be equal to the rotor resistance at standstill multiplied by a factor. Hence, the results were adversely affected by this approximation. A simulation program has been developed to compute the IM parameters using name-plate data as in [15]. No-load and locked rotor tests were implemented on the machine in MATLAB/Simulink environment. Despite simplicity, this method neglected the core loss resistance leading to less sensitive results.

Based on motor geometrical design, certain computational algorithms, such as finite element analysis, have been adopted to compute IM parameters as reported in [16-19]. Saturation and skin 
effect were taken into consideration as well as the leakage reactances were estimated independently. However, this method requires the awareness of the machine dimensional data.

Online estimation of IM parameters has been executed by different techniques for control purposes as in [20-23]. These techniques aim to continuous updating of the parameter's values, in real-time, to cope with expected changes in temperature, saturation and other effects in the machine during the operation. However, these techniques need initial values for motor parameters which already computed by the inverter its self.

This paper adopts a mathematical method to compute the parameters for three groups of Squirrel Cage Induction Motors (SQIMs). The first group consists of eleven motors with two pole number and different power ratings, ranging from $0.75 \mathrm{KW}$ to 18.5 $\mathrm{KW}$. While, the second group comprises eleven motors with four poles and power ratings from $0.55 \mathrm{KW}$ to $15 \mathrm{KW}$. Ultimately, the third group incorporates also eleven motors but with six poles and power ratings from 0.37 to $11 \mathrm{KW}$. These motors are produced by an Egyptian factory according to the specifications licensed by SIEMENS international company. The proposed mathematical equations are deduced based on the full-load data available on the motor name-plate, then used to calculate the parameters for all mentioned motors. To evaluate the proposed method, the conventional equivalent circuit shown in Figure 1 is used to investigate the performance characteristics for each motor at rated condition. The results are then compared to the data provided by name-plates. Acceptable correlation is obtained, enhancing the validity of proposed method.

\section{Induction motor equivalent circuit}

The steady-state mathematical model of a 3phase SQIM is derived based on the equivalent circuit per phase shown in Figure 1.

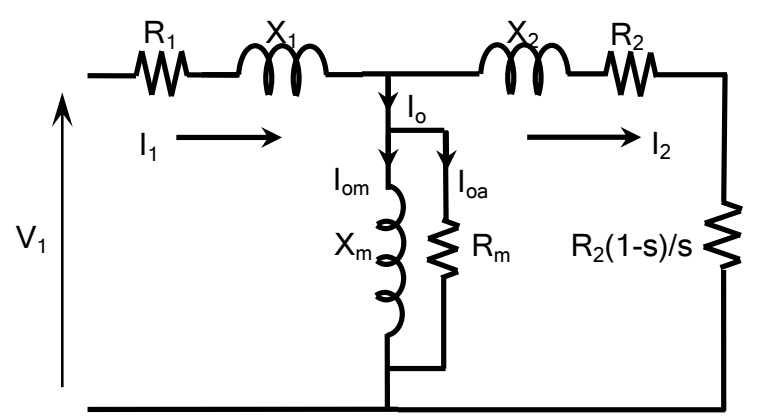

Figure 1 Equivalent circuit per phase of IM

The motor parameters are defined as: $R_{1}$ and $X_{1}$ are the stator phase resistance and leakage reactance receptively. $R_{2}$ represents the rotor phase resistance referred to the stator. $X_{2}$ is the rotor phase leakage reactance at standstill referred to the stator. $R_{m}$ stands for the core loss resistance and $X_{m}$ denotes the magnetizing reactance. These parameters are investigated in the following section.

\section{Mathematical Calculations}

Based on the full-load data available on motor name-plate, a set of equations are derived by trial and error, on which, the six parameters of SQIM equivalent circuit are calculated, assisted by papers [10-13]. The details of computation process are presented as following:

Depending on the previous references, the parameters of motor equivalent circuit can be conventionally computed from the following equations:

$$
\begin{aligned}
& R_{1}=P_{c 1} / 3 I_{1}{ }^{2} \\
& R_{2}=P_{c 2} / 3 I_{2}{ }^{2} \\
& R_{m}=3 E_{1}{ }^{2} / P_{i} \\
& X_{m}=E_{1} / I_{o m} \\
& X_{1}=\sqrt{Z_{1}{ }^{2}-R_{1}{ }^{2}}
\end{aligned}
$$

Where, $P_{c 1}$ is the stator copper loss, $P_{c 2}$ is rotor copper loss and $P_{i}$ is the iron loss. $I_{1}$ denotes the stator current, $I_{2}$ stands for the rotor current referred to stator and $I_{o m}$ represents the reactive component of no- load current. $E_{1}$ is the stator phase emf and $Z_{1}$ represents the stator impedance.

The total losses in the machine at rated condition $\left(P_{\text {loss }}\right)$ is given by:

$P_{\text {loss }}=\left(\frac{1}{\eta_{r}}-1\right) P_{r}$

Where, $\mathrm{P}_{r}$ is the rated output power and $\eta_{r}$ is the rated efficiency. The total losses can be divided into $P_{\text {loss } 1}$ and $P_{\text {loss } 2 \text {. Where }} P_{\text {loss } 1}$ denotes the copper losses in stator and rotor. While, $P_{\text {loss2 }}$ expresses the sum of iron and mechanical losses. They can be defined as:

$$
\begin{aligned}
& P_{\text {loss } 1}=P_{c 1}+P_{c 2}=K_{1} \times P_{\text {loss }} \\
& P_{\text {loss } 2}=P_{i}+P_{f w}=\left(1-K_{1}\right) \times P_{\text {loss }}
\end{aligned}
$$

Where $P_{f w}$ is the mechanical losses at rated condition. $K_{1}$ is a factor expresses the quantity of copper in the machine and is described as a function of rated output power based on the following empirical formula.

$$
K_{1}=\left(0.7 K_{v}-0.05 \log P_{r}\right)
$$

Where $K_{v}$ is a correction factor calculated as a function of rated output power, in kilo watt, based on the following fitted equation.

$$
\begin{aligned}
K_{v}=0.86846822 & +0.14779 P_{r}-0.02662 P_{r}{ }^{2} \\
+ & 0.00216 P_{r}^{3}-0.00008 P_{r}^{4}+8.4564 \\
\times & 10^{-7} P_{r}{ }^{3}
\end{aligned}
$$


$P_{c 2}$ can be written as a function of rated slip $(S)$ and rated output power $\left(P_{r}\right)$ as following:

$$
P_{c 2}=\frac{S}{1-S}\left(P_{r}+P_{f w}\right)
$$

Once, $P_{c 2}$ is obtained, $P_{c 1}$ can be found according to (7). Consequently, the stator resistance $\left(R_{1}\right)$ can be obtained according to (1), after substituting by the rated value of stator current $\left(I_{1}\right)$.

The iron and mechanical losses can be described individually as a ratio of $P_{\text {loss2 }}$ as following:

$$
\begin{aligned}
& P_{i}=K_{2} \times P_{\text {loss } 2} \\
& P_{f w}=\left(1-K_{2}\right) K_{d} \times P_{\text {loss } 2} \\
& K_{2}=\left(0.8 K_{f}-0.1 \log P_{r}\right)
\end{aligned}
$$

Where $K_{2}$ is a factor expresses the quantity of iron in the machine. While, $K_{d}$ and $K_{f}$ are correction factors described as a function of rated output power, in kilo watt, based on the following fitted equations.

$$
\begin{aligned}
K_{d}=3.57512- & 1.23434 P_{r}+0.34342 P_{r}{ }^{2}-0.04953 P_{r}{ }^{3} \\
& +0.00394 P_{r}{ }^{4}-0.00017 P_{r}{ }^{5}+2.8514 \\
& \times 10^{-6} P_{r}{ }^{6} \\
K_{f}=0.60543+ & 0.05685 P_{r}-0.00549 P_{r}{ }^{2}+0.00321 P_{r}{ }^{3} \\
& -0.00062 P_{r}{ }^{4}+0.00004 P_{r}{ }^{5}-1.101 \\
& \times 10^{-6} P_{r}{ }^{6}
\end{aligned}
$$

The stator phase e.m.f $\left(E_{1}\right)$ is computed from the following equation:

$$
E_{1}=\left(0.65 K_{x}-0.05 \log P_{r}\right) V_{1}
$$

Where $V_{1}$ is the rated stator voltage that equal to $380 \mathrm{v}$ for all investigated motors as mentioned previously. Whereas, $K_{x}$ is a correction factor expressed as a function of rated output power, in kilo watt, based on the following fitted equation.

$$
\begin{aligned}
K_{x}=0.87339+ & 0.09319 P_{r}-0.00709 P_{r}^{2} \\
& +0.00017 P_{r}^{3}
\end{aligned}
$$

By the information of $P_{i}$ from (12) and $E_{1}, R_{m}$ can be found according to (3)

To obtain $R_{2}$, rotor current $\left(I_{2}\right)$ should be computed, firstly. It can be derived from the equivalent circuit, with the knowledge of stator current $\left(I_{1}\right)$ and noload current $\left(I_{0}\right)$. By the information of power factor $(\cos \varphi)$ and $l_{1}$ at rated condition from name-plate data, $I_{1}$ becomes available with its real and imaginary components. In terms of $\left(I_{0}\right)$, it has also two components. They are: $l_{o a}$ denoting the active component and $I_{o m}$ representing the reactive component. $I_{o a}$ is given by:

$$
I_{o a}=P_{i} / 3 E_{1}
$$
equation.

While, Iom can be computed from the following

$$
\underline{I_{o m}}=I_{1} \sin \varphi-I_{1}\left[M-\sqrt{M^{2}-1}\right]
$$

Where $M$ is the ratio of maximum torque to rated torque provided in motor data sheet.

Hence, $I_{2}$ can be derived as:

$$
I_{2}=\sqrt{\left(I_{1} \cos \varphi-I_{o a}\right)^{2}+\left(I_{1} \sin \varphi-I_{o m}\right)^{2}}
$$

Thus, $R_{2}$ can be obtained according to (2).

Based on $E_{1}$ and $I_{o m}$, the magnetizing reactance $\left(X_{m}\right)$ can be obtained according to (4).

Based on the equivalent circuit, the stator impedance $\left(Z_{1}\right)$ can be calculated from the following vectorial equation:

$$
Z_{1}=\frac{V_{1}-E_{1}}{I_{1}}
$$

The magnitude of vector $E_{1}$ is known. While its angle can be simply computed based on the angle of no-load current $\left(I_{0}\right)$ and the angle of the equivalent impedance of $R_{m}$ and $X_{m}$.

Once, $Z_{1}$ is calculated, $X_{1}$ can be obtained from (5), since $R_{1}$ is derived previously. Furthermore, $X_{2}$ can be assumed to be equal $X_{1}$ for SQIMs.

\section{Parameters Identification}

In this section, a case study is performed to apply the proposed methodology to the three groups of SIEMENS SQIMs, indicated before, for extracting their parameters based on their full-data. Plotting the motor parameters as a function of rated output power is a good tool to facilitate the parameter estimation. The results are discussed as following:

Figure 2 demonstrates the variation of stator resistance against rated output power for investigated motors. It seems obviously that the curves are convergent. On the other hand, the rotor resistance is computed against rated output power for investigated motors as shown in Figure 3. It is observed that, for low power range, the rotor resistance curve of six-pole motors increases over the curve of four-pole motors which is also greater than the curve of two-pole motors. While with the power increase, the curves are close to each other. Figure 4 illustrates the variation of iron loss resistance against rated output power for investigated motors. The curves are also convergent.

As mentioned previously, the rotor reactance is assumed to be equal the stator reactance for SQIMs. Hence, Figure 5 exhibits the variation of stator leakage reactance only, against rated output power. It is clear that the curves are convergent. In other words, the change of magnetizing reactance with the rated output power of studied motors is indicated by Figure. 6. It is observed that the magnetizing reactance curve of twopole motors increases over the curve of four-pole motors which also is greater than the curve of six-pole motors. 


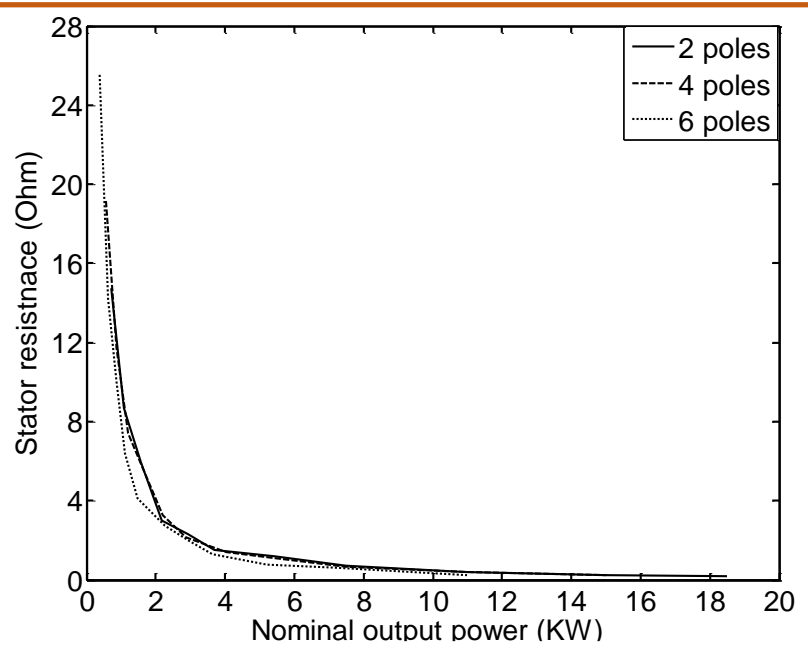

Figure 2 Variation of stator resistance with rated output power for the three groups of SIEMENS SQIMs.

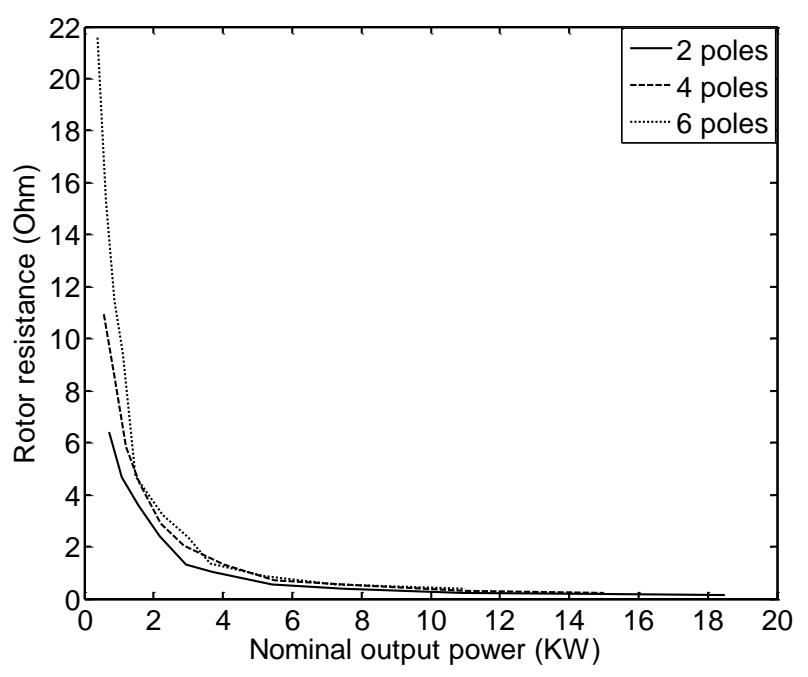

Figure 3 Variation of rotor resistance with rated output power for the three groups of SIEMENS SQIMs

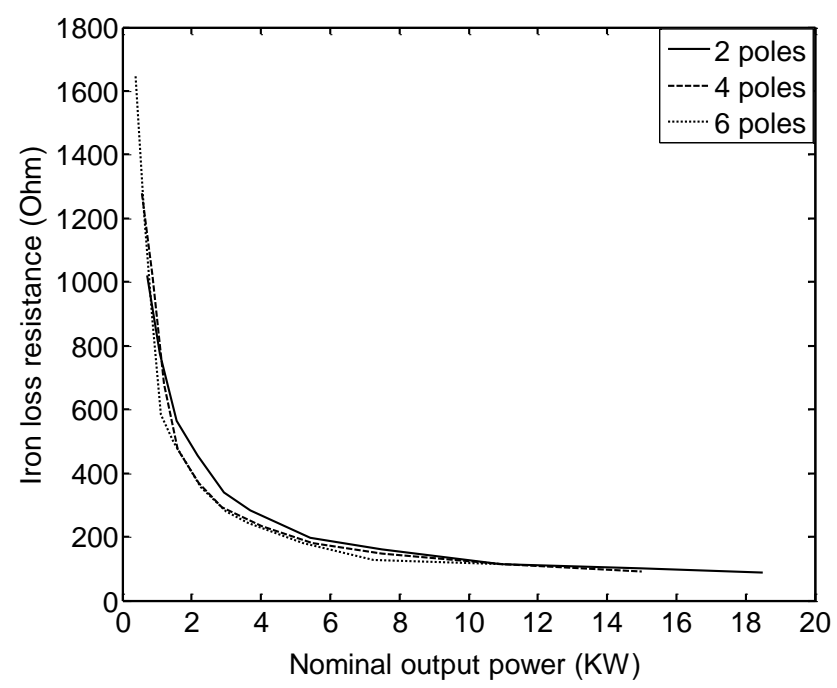

Figure 4 Variation of iron loss resistance with rated output power for the three groups of SIEMENS SQIMs

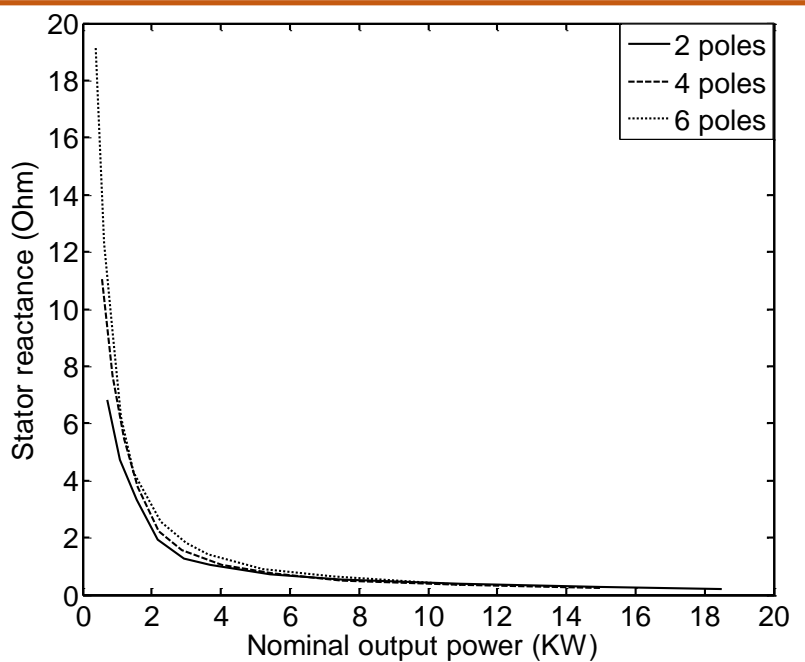

Figure 5 Variation of stator leakage reactance against rated output power for the three groups of SIEMENS SQIMs

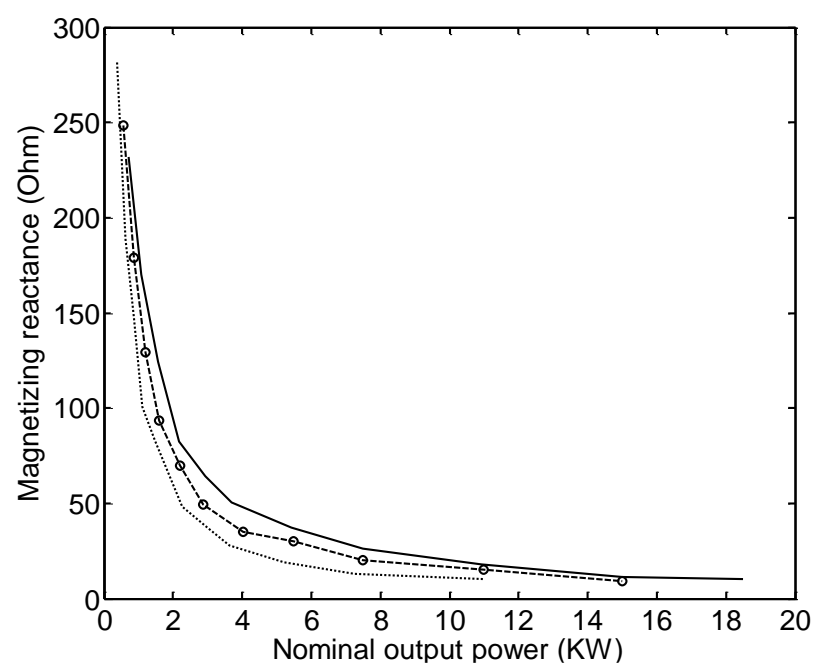

Figure 6 Variation of magnetizing reactance with rated output power for the three groups of SIEMENS SQIMs

\section{Motor performance investigation}

On the basis of conventional calculations concerning the equivalent circuit as well as parameters values computed previously, the performance characteristics of the three groups of SIEMENS SQIMs, indicated previously, are investigated at full-load condition. The results are discussed as following:

Figure 7 demonstrates the variation of computed efficiency at full-load against the nominal output power for all the different groups of investigated motors. The power factor is also predicted at full-load for the specified motor groups and plotted against the nominal output power as shown in Figure 8 . It can be observed, from these two figures, that two-pole motors have superior efficiency and power factor curves. While two-pole motors have inferior efficiency and power factor curves. This attributes to the design basics. 


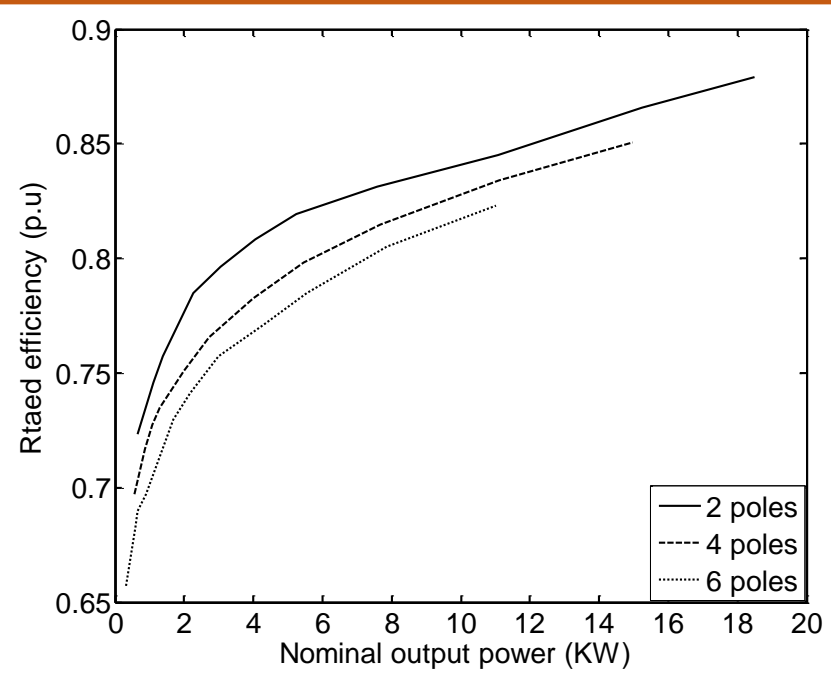

Figure 7 Estimated efficiency at full-load against rated output power for the three groups of SIEMENS SQIMs

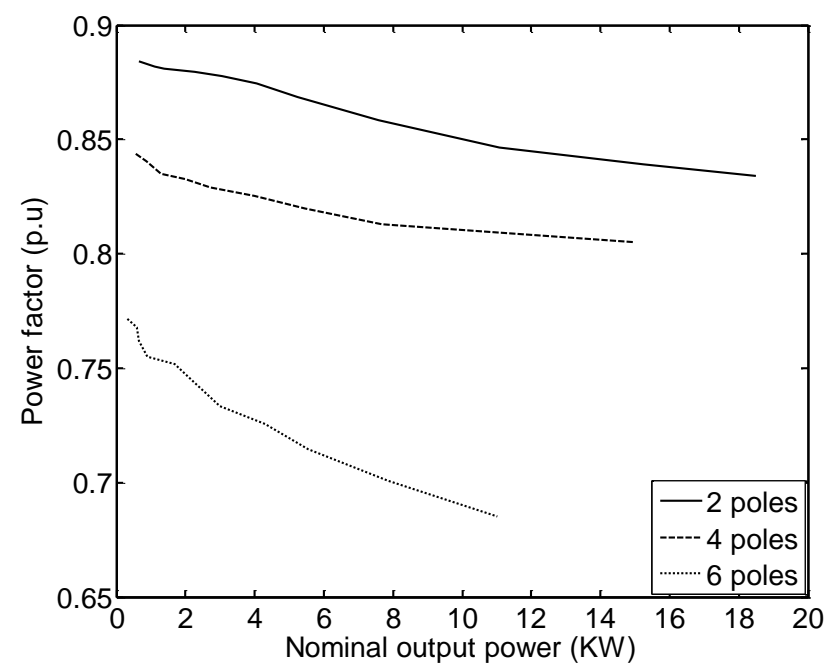

Figure 8 Estimated power factor at full-load against rated output power for the three groups of SIEMENS SQIMs

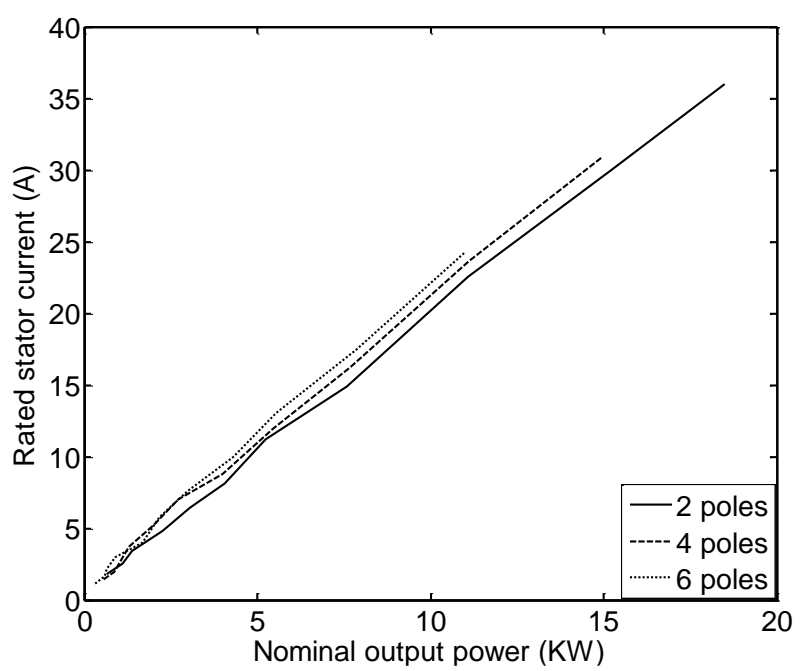

Figure 9 Estimated stator current at full-load against rated output power for the three groups of SIEMENS SQIMs

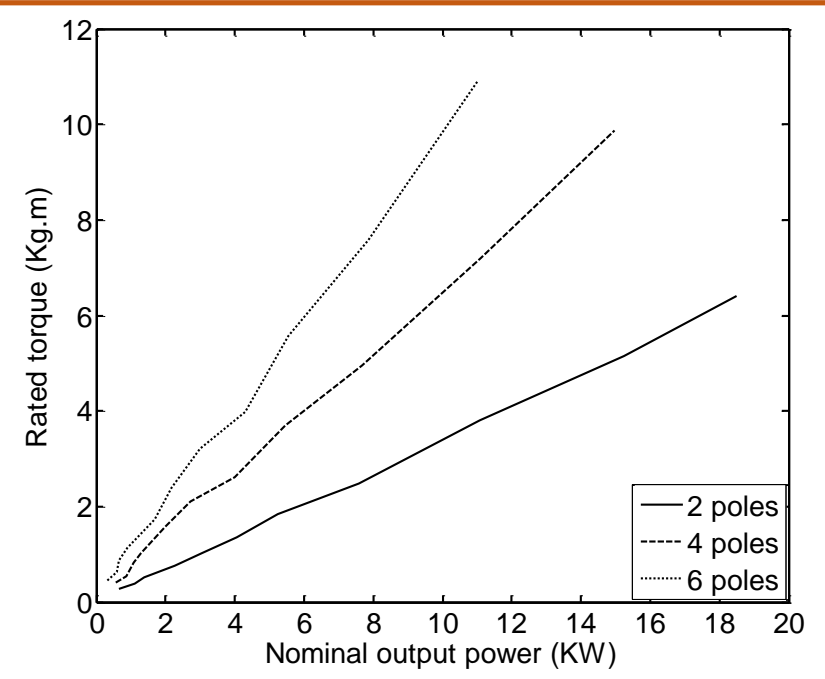

Figure 10 Estimated output torque at full-load against rated output power for the three groups of SIEMENS

IMs

Figure 9 exhibits the variation of stator current, computed at full-load, against the nominal output power for the investigated motors. It is clear that the stator current increases as the output power as well as the machine pole number increase. Finally, the full-load torque values are predicted for the studied motors and plotted against the nominal output power as indicated by Figure 10. It is observed that, six-pole motors have a superior torque curve followed by four-pole motors then two-pole motors. This is due to the inverse relationship between the torque and the speed, which is inversely proportional to the machine pole number, at the same output power. The full-load performance characteristics, estimated previously, were compared to their counterparts in data sheets of investigated motors. Acceptable agreement is obtained, reflecting the validity of proposed method.

\section{Conclusion}

In the present work, a developed mathematical approach is proposed to determine the parameters for thirty-three standard IMs, authorized by SIEMENS international company. The performance characteristics of these motors are calculated based on the estimated parameters for evaluating the proposed method. The results achieve satisfactory correlation with the full-load data available in the data sheets of investigated motors. This enhances the effectiveness of the proposed method.

\section{References}

[1] X.W.W. Huang, X. Lin, W. Jiang, Y. Zhao, S. Zhu, Direct torque control for induction motors based on minimum voltage vector error, IEEE Transactions on Industrial Electronics, 68 (2021) 3794-3804. [DOI]

[2] S.R. Eftekhari, S.A. Davari, P. Naderi, C. 
Garcia, J. Rodriguez, Robust loss minimization for predictive direct torque and flux control of an induction motor with electrical circuit model, IEEE Transactions on Power Electronics, 35 (2020) 5417-5426. [DOl]

[3] B.R. Vinod, G. Shiny, Direct torque control scheme for a four-level-inverter fed open-endwinding induction motor, IEEE Transactions on Energy Conversion, 34 (20190) 2209-2217. [DOI]

[4] R. Rai, S. Shukla, B. Singh, Sensorless field oriented SMCC based integral sliding mode for solar PV based induction motor drive for water pumping, IEEE Transactions on Industry Applications, 56 (2020) 5056-5064. [DOI]

[5] J.R. Dom'ınguez, I. Duenas, S. OrtegaCisneros, Discrete-time modeling and control based on field orientation for induction motors, IEEE Transactions on Power Electronics, 35 (2020) 8779-8793. [DOl]

[6] M.J. Cheerangal, A.K. Jain, A. Das, Control of rotor field-oriented induction motor drive during input supply voltage sag, IEEE Journal of Emerging and Selected Topics in Power Electronics, 9 (2021) 2789-2796. [DOl]

[7] M. Carraro, M. Zigliotto, Automatic parameter identification of inverter-fed induction motors at standstill, IEEE Transactions on Industrial Electronics, 61 (2014) 4605-4613. [DOl]

[8] K. Yamazaki, A. Suzuki, M. Ohto, T. Takakura, Circuit parameters determination involving stray load loss and harmonic torques for highspeed induction motors fed by inverters, IEEE Transactions on Energy Conversion, 28 (2013) 154-163. [DOI]

[9] J. Xiaochun, Y. Geng, W. yunfei, A parameter identification method for general inverter-fed induction motor drive, International Conference on Power Electronics and Motion Control, Shanghai, China, (2006) 1-5.

[10] C.A.C. Wengerkievicz, R.A. Elias, N.J. Batistela, N. Sadowski, P. Kuo-Peng, S. C. Lima, P. A. da Silva Jr., A. Y. Beltrame, Estimation of three-phase induction motor equivalent circuit parameters from manufacturer catalog data, Journal of Microwaves Optoelectronics and Electromagnetic Applications, 16 (2017) 90107. [DOI]

[11] S.C. Lima, C.A.C. Wengerkievicz, N.J. Batistela, N. Sadowski, P.A. da Silva Jr, A.Y. Beltrame, Induction motor parameter estimation from manufacturer data using genetic algorithms and heuristic relationships, International Conference Power Electronics, Juiz de Fora, Brazil, (2017) 1-6. [DOl]

[12] S.C. Sabharwal, Methodology for estimating performance characteristics of three phase induction motor operating direct-on-line or with six pulse inverter, International Conference on Power Electronic Drives and Energy Systems, New Delhi, India, (2006) 1-4. [DOl]

[13] G.F.V. Amaral, J.M.R. Baccarini, F.C.R. Coelho, L.M. Rabelo, A high precision method for induction machine parameters estimation from manufacturer data, IEEE Transactions on Energy Conversion, 36 (2021) 1226-1233. [DOI]

[14] M.H. Haque, Determination of NEMA design induction motor parameters from manufacturer data, IEEE Transactions on Energy Conversion, 23 (2008) 997-1004. [DOl]

[15] A.R. Helonde, M. Mankar, Identifying three phase induction motor equivalent circuit parameters from nameplate data by different analytical methods, International Journal of Trend in Scientific Research and Development, 3 (2019) 642-645. [DOl]

[16] Z. Ling, L. Zhou, S. Guo, Y. Zhang, Equivalent circuit parameters calculation of induction motor by finite element analysis, IEEE Transactions on Magnetics, 50 (2014) 833836. [DOI]

[17] J. Faiz, M.B.B. Sharifian, M.R. Feyzi, K. Shaarbafi, A complete lumped equivalent circuit of three-phase squirrel-cage induction motors using two-dimensional finite-elements technique, IEEE Transactions on Energy Conversion, 17 (2002) 363-367. [DOl]

[18] A. Boglietti, A. Cavagnino, M. Lazzari, Computational algorithms for induction-Motor equivalent circuit parameter determinationpart I: resistances and leakage reactances, IEEE Transactions on Industrial Electronics, 58 (2011) 3723-3733. [DOI]

[19] A. Boglietti, A. Cavagnino, M. Lazzari, Computational algorithms for induction-Motor equivalent circuit parameter determinationpart II: skin effect and magnetizing characteristics, IEEE Transactions on Industrial Electronics, 58 (2011) 3734-3740. [DOI]

[20] M. Wlas, Z. Krzeminski, H.A. Toliyat, Neuralnetwork-based parameter estimations of induction motors, IEEE Transactions on Industrial Electronics, 55 (2008) 1783-1794. [DOI]

[21] D. Bhowmick, M. Manna, S.K. Chowdhury, Estimation of equivalent circuit parameters of transformer and induction motor from load data, IEEE Transactions on Industry Applications, 54 (2018) 2784-2791. [DOI]

[22] L. Shanshan, Z. Ninghui, W. Biao, F. Yunji, Online parameter identification of a squirrel cage induction motor, Journal of Physics: Conference Series, 1302 (2019) 1-7. [DOl]

[23] Grantham, D.J. McKinnon, Rapid parameter 
determination for induction motor analysis and control, IEEE Transactions on Industry Applications, 39 (2003) 1014 - 1020. [DOI]

\section{Funding}

No funding was received for conducting this study.

\section{Conflict of interest}

The Author has no conflicts of interest to declare that they are relevant to the content of this article.

Does this article screened for similarity?

Yes

\section{About the License}

(C) The Author 2022. The text of this article is open access and licensed under a Creative Commons Attribution 4.0 International License 